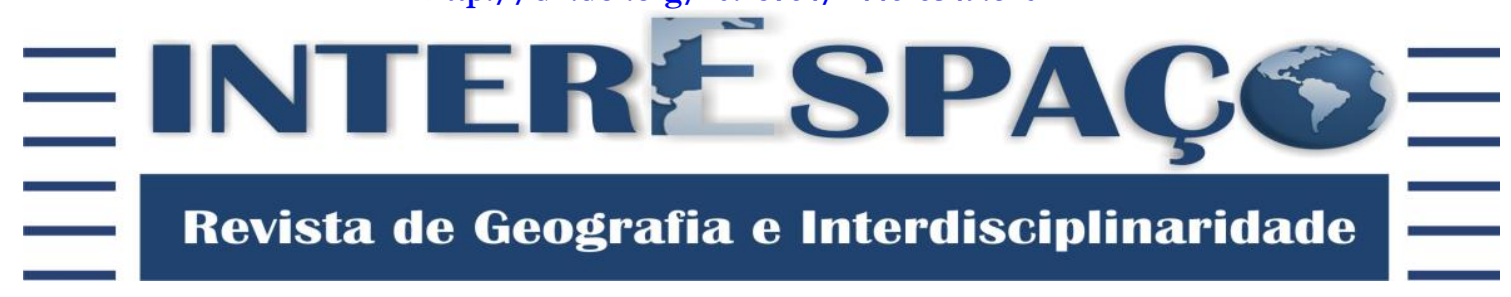

\title{
TESSITURAS DE UM TERRITÓRIO: o policiamento escolar na Grande Belém ${ }^{1}$
}

TERRITORIAL MESHES: school policing in Greater Belém

TESITURAS DE UN TERRITORIO: policía escolar en la Grande Belém

\begin{abstract}
Leildo Dias Silva
Mestre em Planejamento do Desenvolvimento pelo Núcleo de Altos Estudos Amazônicos da Universidade Federal do Pará - NAEA/UFPA. Professor da Secretaria de Estado da Educação do Pará (SEDUC).

leildodias89@gmail.com; leildo.silva@naea.ufpa.br / http://orcid.org/0000-0003-1227-1433
\end{abstract}

Recebido: 23/05/2020; Aceito: 29/01/2021; Publicado: 28/06/2021.

\section{RESUMO}

É da natureza do Estado produzir recortes/tessituras territoriais para exercer o seu poder das mais diversas maneiras. Consoante a isso, esta pesquisa tem como tema as tessituras da segurança pública do estado do Pará com vistas ao policiamento escolar. Objetiva-se analisar a produção de tais tessituras e sua utilização pela Companhia Independente de Policiamento Escolar (CIPOE) nos municípios de Belém, Ananindeua e Marituba. Para tanto, adotamos o seguinte procedimento metodológico: 1) revisão de literatura especializada; 2) trabalhos de campo; 3) catalogação/tabulação dos dados; e 4) interpretação e análise dos dados. Os resultados apontam que as instituições/órgãos responsáveis pela segurança pública, no estado do Pará, produzem, via legislação, uma série de malhas territoriais, tais como as Regiões Integradas de Segurança Pública e Defesa Social (RISPs), as Áreas Integradas de Segurança Pública e Defesa Social (AISPs) e as áreas de atuação dos Batalhões de Polícia Militar (BPM). Como conclusões, podemos afirmar que a CIPOE se utiliza dos recortes territoriais da segurança pública do Pará, ao passo que, também, produz suas próprias malhas.

Palavras-chave: CIPOE; Policiamento Escolar; Território; Malhas Territoriais.

\section{ABSTRACT}

It is in the nature of the State to produce territorial cuts/limits to exercise its power in the most diverse ways. Therefore, this research has as theme the territorial meshes of public security in the state of Pará with a view to school policing. The aim of this research is to analyze the production of these limits and their use by the Companhia Independente de Policiamento Escolar - CIPOE, in the municipalities of Belém, Ananindeua and Marituba. Thus, as a methodological procedure we adopted: 1) review of specialized literature; 2) fieldwork; 3) data tabulation and 4) data interpretation and analysis. The results conclude the institutions/public agencies responsible for public security in the state of Pará, produce through legislation a series of territorial meshes, such as Integrated Regions of Public Security and Social Defense, Integrated Areas of Public Security and Social Defense, areas of activity of Military Police Battalions, etc. As conclusions, we can affirm that CIPOE uses the territorial cuts of public security in Pará as it also produces its own meshes.

\footnotetext{
${ }^{1}$ O presente artigo é fruto das atividades desenvolvidas no grupo de pesquisa: Defesa, Fronteira e Políticas Públicas, vinculado ao Núcleo de Altos Estudos Amazônicos (NAEA), Universidade Federal do Pará (UFPA).
} 
Keywords: CIPOE; School Policing; Territory; Territorial Meshes.

\section{RESUMEN}

Está en la naturaleza del Estado producir cortes/fabricaciones territoriales para ejercer su poder de las más diversas maneras. Ante eso, esta investigación tiene como tema las fabricaciones de seguridad pública en el estado de Pará con miras a la vigilancia escolar. El objetivo es analizar la producción de los cortes territoriales y su uso por parte de la Companbia Independente de Policiamento Escolar (CIPOE) en los municipios de Belém, Ananindeua y Marituba. Para tal fin, hemos adoptado el siguiente procedimiento metodológico: 1) revisión de literatura especializada; 2) trabajo de campo; 3) catalogación/tabulación de datos e 4) interpretación y análisis de datos. Los resultados apuntan que las instituciones y los órganos responsables por la seguridad pública, en el estado de Pará, producen, vía legislación, una serie de mallas territoriales, tales como las Regiões Integradas de Segurança Pública e Defesa Social (RISPs), las Areas Integradas de Segurança Pública e Defesa Social (AISPs) y las áreas de actuación de los Batalhôes de Policia Militar (BPMs). Como conclusiones, se puede afirmar que la CIPOE utiliza los recortes territoriales de seguridad pública de Pará, ya que también produce sus propias mallas.

Palabras clave: CIPOE; Policía Escolar; Territorio; Mallas Territoriales.

\section{INTRODUÇÃO}

"A tessitura é sempre um enquadramento do poder ou de um poder. A escala da tessitura determina a escala dos poderes" (RAFFESTIN, 1993, p. 154). Recorrer, inicialmente, a essa citação significa marcar um lugar entre a literatura especializada. Em conformidade com esses apontamentos, o nosso tema de pesquisa traz à tona a produção das tessituras da segurança pública do estado do Pará, como espaços de exercícios de poder de polícia do Estado, com vistas ao policiamento promovido pela Companhia Independente de Policiamento Escolar (CIPOE). Os exercícios de poder e controle penetram as instituições e indivíduos dentro de suas malhas. Dentre esses exercícios, o policiamento escolar é um exemplo do refinamento dos mecanismos disciplinares e de controle da sociedade brasileira, e seus efeitos não agem somente sobre a escola, mas também sobre a sociedade. Apesar dessas implicações, esse fenômeno ainda é pouco pesquisado, conforme demonstra a escassez de literatura especializada.

Inicialmente, é oportuno ressaltar para o leitor que o policiamento escolar, na Grande Belém, é efetuado pela CIPOE, ligada à Polícia Militar do Estado do Pará (PM). Segundo o Decreto n ${ }^{\circ}$ 1.625, de 18 de outubro de 2016, em seu artigo 259, “[...] compete à CIPOE, no que couber, executar as atividades constantes do art. 211 deste Regulamento, bem como executar policiamento ostensivo fardado nas escolas públicas estaduais e municipais" (PARÁ, 2016, p. 52).

Além do policiamento escolar, algumas das outras competências da CIPOE, constantes no artigo 211 do referido decreto, são: administração da Unidade, atualização da carta da área de sua atuação, análise criminal e georreferenciamento da área de sua 


\section{| Leildo Dias Silva |}

circunscrição, elaboração do plano de atuação em sua área, estabelecimento de rotina e procedimentos de atuação. No Pará, a atuação dessa companhia se limita, praticamente, às cidades de Belém, Ananindeua e Marituba, efetivando-se dentro e no entorno das escolas estaduais e municipais. Seu objetivo é "preservar e manter a ordem" (ou o que é entendido como tal pela companhia) podendo, inclusive, haver repressão para que esse propósito seja alcançado.

Dito isso, o objetivo, neste artigo, é analisar a produção das tessituras do território da segurança pública do estado do Pará e investigar como a CIPOE usa essas tessituras ao mesmo tempo em que também produz as suas próprias. O esforço, aqui, é conseguir realizar, a partir da referida companhia, a análise sobre os usos, as inserções e as produções dessas malhas da segurança púbica do referido estado, com vistas ao policiamento escolar.

Para tanto, como procedimentos metodológicos, seguimos alguns passos. Primeiro, revisamos a literatura "especializada" que pudesse nos dar suporte no entendimento acerca da produção das tessituras de um determinado território. Nesse ponto, tivemos que lidar com o desafio da quase completa ausência de bibliografia específica sobre a CIPOE. Todavia, buscamos, em autores que problematizam a categoria "território" ou temas relacionados, o suporte para enfrentar o desafio e, assim, aproximamo-nos das reflexões promovidas por Raffestin (1993; 2008; 2012), Saquet (2006; 2008; 2013), Souza (1995; 2008; 2013) e Foucault (2004 [1979]; 2008).

Segundo, realizamos trabalhos de campo junto à companhia, por meio dos quais tivemos acesso ao Plano de Gestão CIPOE 2016-2018 (PGCIPOE), e pudemos entrevistar agentes ${ }^{2}$ da CIPOE, o que nos ajudou a ampliar as reflexões aqui propostas. Ainda neste segundo momento, analisamos as legislações que tratam da criação das malhas/tessituras da segurança pública do estado do Pará. Terceiro, organizamos as informações contidas na legislação estadual e no PGCIPOE de nosso interesse para a elaboração de mapas e de um quadro. E, por fim, realizamos as reflexões que julgamos necessárias de acordo com nosso quadro teórico.

O presente artigo, além dessa introdução, apresenta as seguintes seções/subseções: território e tessituras de um poder disciplinar; Estado, 'máquina' de recortar o espaço: os territórios da segurança pública e seus usos pela CIPOE; CIPOE: as tessituras do território do policiamento escolar na Grande Belém e, por fim, as conclusões.

\section{TERRITÓRIO E TESSITURAS DE UM PODER DISCIPLINAR}

\footnotetext{
${ }^{2}$ Realizamos cinco entrevistas com agentes da CIPOE, mas, na presente pesquisa, somente iremos fazer uso da entrevista com o Comandante da companhia, em 2017.
} 


\section{|Leildo Dias Silva |}

Nesta pesquisa, em função do nosso objeto de estudo - a CIPOE, uma política de segurança pública do estado do Pará ligada à PM e, portanto, uma política executada pelo Estado - realizamos algumas escolhas teóricas e metodológicas necessárias que fossem coerentes com a problemática analisada, que consiste na produção das tessituras do policiamento escolar e na territorialidade da CIPOE em alguns municípios da Região Metropolitana de Belém. Porém, devemos destacar que, simultaneamente a essa produção, a companhia também faz uso das malhas elaboradas pela segurança pública do estado do Pará.

A respeito de território e territorialidade, vamos tomar como suporte teórico/metodológico Raffestin (1993; 2008; 2012); Saquet (2006, 2008; 2013) ${ }^{3}$ e Souza $(1995 ; 2008 ; 2013)^{4}$. Também iremos nos aproximar das reflexões promovidas por Foucault (2004[1979]; 2008) acerca da categoria “disciplina” para entender a atuação da CIPOE e ampliar as reflexões sobre essa companhia.

Entendemos que há outras linhas de interpretações sobre território e territorialidade, as quais têm grande relevância na Ciência Geográfica. A escolha de Raffestin (1993; 2008; 2012) se deu em função da contribuição que esse autor nos oferece sobre a produção territorial e o sistema territorial, com vistas, aqui, às tessituras. De tal modo, compreendemos que sua análise sobre esses conceitos seja viável (com as ressalvas e adaptações necessárias) à reflexão acerca da produção e do sistema territorial da CIPOE, sendo essa companhia o principal ator (sintagmático) na produção do território do policiamento escolar.

Em nossa leitura, os autores citados anteriormente têm em comum o conceito de "poder", sobretudo aquele teorizado por Foucault. Logicamente, nem todos esses autores concordam em sua plenitude com as abordagens de poder foucaultiana; contudo, as tomam como base para entender as relações e exercício de poder para além do Estado e de suas instituições. O foco desses autores está, também, no poder capilarizado.

Sobre os trabalhos de Foucault, tomaremos como base alguns textos do livro Microfísica do Poder (2004), com destaque aos conceitos de "poder" e "disciplina" e do livro Segurança, território e população (2008), com ênfase, também, no poder e na disciplina. Além desses, o conceito de "polícia" também é importante em seu processo

\footnotetext{
${ }^{3}$ Estamos cientes de que Saquet $(2006$; 2008; 2013) difere de Raffestin quanto à concepção de espaço. Saquet diz que concorda com os trabalhos de Lefebvre, o qual toma o espaço como uma construção social e histórica.

${ }^{4}$ Nesta pesquisa, interessa-nos a dimensão política do território em Souza (1995; 2008; 2013). Contudo, compreendemos que sua construção acerca do território vai além da dimensão política. É, também, econômica, cultural, imaterial/material.
} 


\title{
| Leildo Dias Silva |
}

histórico de constituição de sentido e significados, pois, entendemos que a CIPOE tem, como uma de suas práticas ou territorialidades, o exercício do poder por meio da disciplina.

Acerca do território, nos interessa sua dimensão política trabalhada nos autores já citados. Queremos demarcar, logo de início, que, entre os autores que discutiram território, demos centralidade às pesquisas de Raffestin (1993; 2008; 2012). Sobre Raffestin, Saquet (2006, p. 72) enfatiza a dimensão política do seu conceito de território: "Raffestin destaca o caráter político do território. Após fazer uma reflexão crítica sobre concepções de poder centradas na atuação do Estado, propugna, tendo como uma de suas principais referências Michel Foucault, em favor de distintas variantes do poder [...]."

Explicitado isso, centremos a atenção nos conceitos de território e territorialidade:

\begin{abstract}
O território se forma a partir do espaço, é o resultado de uma ação conduzida por um ator sintagmático [...] em qualquer nível. Ao se apropriar de um espaço, concreto ou abstratamente [...], o ator "territorializa" o espaço. O território [...] é um espaço onde se projetou um trabalho, seja energia e informação, e que, por consequência, releva relações marcadas pelo poder (RAFFESTIN, 1993, p. 128).
\end{abstract}

Por meio das reflexões teóricas citadas, podemos estabelecer algumas aproximações com nosso objeto de análise. Nesse sentido, entendemos que a CIPOE, ao planejar e executar suas ações sobre um dado espaço, configura-se como um ator sintagmático, ou seja, que produz território. A escala de produção desse território é o espaço que compreende as cidades de Belém, Ananindeua e Marituba. A CIPOE utiliza esse espaço já produzido, projetando trabalho (energia e informação) por meio das rondas escolares, do atendimento de ocorrência em ambiente escolar, da produção de planos de segurança escolar e das operações especiais (por exemplo, as operações "voltas às aulas" e "raio escolar"). Entendemos que essas ações da companhia se constituem em relações de poder, das quais resultam a produção de territórios disciplinares e de controle.

Para que haja produção territorial, são necessários atores, trabalho (energia e informação), mediadores materiais, programa do ator e relações efetivadas com o ambiente natural e social. O resultado dessas relações é o território e a territorialidade (RAFFESTIN, 2008; 2012). É importante dizer que os atores/elementos na representação da produção territorial não são, em si, o sistema territorial, embora esse seja, em alguma medida, resultado da produção do território mostrado anteriormente. O sistema territorial, em Raffestin (1993, p. 151), apresenta três elementos ou "[...] subconjuntos estruturais que sustentam a prática social”. São eles: as tessituras/malhas (limites), os nós (pontos) e as redes (linhas). 


\title{
|Leildo Dias Silva |
}

Aproximando-nos da discussão já apresentada, podemos, em termos analíticos, dizer que o Estado e a própria CIPOE (que também é Estado) elaboram um sistema territorial que sustenta suas práticas sociais e que, ao mesmo tempo, é fruto delas. A rigor, pode-se inferir que o sistema territorial da CIPOE (Estado) se apresenta como:

a) Malhas/tessituras — na Grande Belém, são as Regiões Integradas de Segurança Pública e Defesa Social (RISPs), as Áreas Integradas de Segurança Pública e Defesa Social (AISPs), as áreas de atuação dos Batalhões de Polícia Militar (BPM) e os Setores Territoriais de Policiamento Escolar (STs);

b) nós - corresponde aos centros de poder e decisões do policiamento escolar hierarquizados, como o Comando Geral de Polícia Militar do Pará, o Comando de Policiamento Especializado, Centro Integrado de Operações (CIOp) ${ }^{5}$, as unidades física dos BPM, a unidade física/administrativa da CIPOE, as delegacias de polícia, a Divisão de Atendimento ao Adolescente (DATA), etc.; ${ }^{6}$

c) redes - a rede rádio, rotas de planejamento operacional e o policiamento ordenado, bem como as linhas (rotas) de informação física e remotas de informações (telecomunicações) e inteligência, são redes. ${ }^{7}$

Desses três elementos que sustentam as práticas socioespaciais, apresentados por Raffestin (1993, p. 153), queremos destacar as tessituras/malhas. Essas implicam sempre o sentido de limites: "[...] definir, caracterizar, distinguir, classificar, decidir, agir implicam a noção de limite: é preciso delimitar”. E prossegue:

\begin{abstract}
Delimitar é, pois, isolar ou subtrair momentaneamente ou, ainda, manifestar um poder numa área precisa. O desenho de uma malha ou de um conjunto de malhas é a consequência de uma relação com o espaço e, por conseguinte, a forma mais elementar da produção de território. É evidente que se pode tecer uma superfície de uma infinidade de maneiras. Na realidade, tal não é o caso, pois o sistema de objetivos e de ações é sempre guiado por uma série de princípios que revelam uma ordem, hierárquica ou não. A tessitura territorial pode comportar níveis que são determinados pelas funções que devem se realizar em cada uma dessas malhas (Ibid., p. 153).
\end{abstract}

$\mathrm{Na}$ prática de delimitar e recortar o espaço, há sempre um projeto/programa determinado para tais recortes, os quais seguem princípios e têm funções a desempenhar.

\footnotetext{
${ }^{5}$ Se tratando de ocorrência de violência na escola, esta aciona o CIOp que em seguida aciona a CIPOE.

${ }^{6}$ Entendemos que a SEDUC configura-se como nó, uma vez que é um centro de comando. Contudo, os recortes territoriais que são produzidos por ela, a exemplo das áreas de atuação das Unidades Regionais de Ensino (URE), são malhas.

7 As Rondas Escolares Ordinárias e os Atendimentos de Ocorrências Escolares são movimentos dentro dos limites das malhas. Ainda é importante mencionar que há diversos meio de comunicação não visíveis no espaço (por exemplo, ligação telefônica, e-mail, ofícios etc.) e, portanto, de ligação entre os nós dentro do território que estamos chamando de território do policiamento escolar.
} 


\section{| Leildo Dias Silva |}

São funções de controle, vigilância, contenção etc. (HAESBAERT, 2014). No caso do território do policiamento em Belém, Ananindeua e Marituba, as funções sofrem variações conforme os recortes das malhas. Por exemplo, o Comando de Policiamento da Capital tem incumbência de gestão/controle da $1^{\text {a }}$ RISP; em cada AISP, tem-se uma unidade de administração do referido território e os STs são administrados e controlados pela CIPOE. Essas malhas são todas do Estado. Nesses termos, podemos nos aproximar de Raffestin (1993, p. 39) ao ressaltar que “[...] o Estado só recorta o espaço em malhas mais ou menos cerradas por uma única razão: deve encontrar a 'malha' mais adequada para, levando em consideração os seus meios, 'ver' o melhor possível”.

Outro autor que nos ajuda na reflexão é Marcelo Lopes de Souza (1995; 2008; 2013). Apesar de sabermos que ele não faz uso de um sistema territorial, como faz Raffestin, a sua discussão de território também ganha importância em nossa pesquisa, sobretudo a dimensão política de sua abordagem. Acerca do território, diz:

\footnotetext{
[...] eu comparei o território a um "campo de força": ele é, obviamente, um aspecto, uma dimensão do espaço social, e ele depende, de várias maneiras, da dimensão material do espaço; mas ele é, em si mesmo, intangível, assim como também o poder é impalpável, como relação social que é. O poder é uma relação social (ou, antes, uma dimensão das relações sociais), e o território é a expressão espacial disso. A existência do território é impossível e inconcebível sem o substrato espacial material, da mesma maneira que não se exerce o poder sem contato com e referência à materialidade em geral; ao mesmo tempo, porém, o território não é redutível ao substrato, não devendo ser com ele confundido [...] (SOUZA, 2008, p. 66).
}

Mesmo nós discutindo um território do Estado, estamos ciente de que há muitos outros territórios e agentes territoriais na área em que este estudo se deu. Na produção do território do policiamento escolar, há um campo de forças e há disputas entre os atores envolvidos nessa produção. Podemos citar, como exemplo, a resistência de parte do corpo docente sobre o policiamento em ambiente escolar; inclusive, há professores e diretores que defendem o policiamento por não militares, criticam o policiamento executado pela $\mathrm{PM}^{8}$.

O território, como se sabe, resulta das práticas sociais e é mantido por elas, o que, na Geografia, denominamos "territorialidade". Esse conceito é fundamental ao estudo que aqui estamos fazendo. Acerca desse conceito, concordamos com os encaminhamentos apontados por Raffestin (2012), Souza (2008) e Saquet (2013). A respeito da territorialidade, Raffestin (2012, p. 139) afirma: “[...] territoriality is the ensemble of relations that humans maintain with exteriority and alterity, with the assistance of

\footnotetext{
${ }^{8}$ Dias Silva (2020) traz, no bojo de sua pesquisa de dissertação, esses conflitos e disputas em torno do policiamento escolar.
} 


\section{|Leildo Dias Silva |}

mediators, for the satisfaction of their needs, towards the end of attaining the greatest possible autonomy [...] taking into account the resources of the system"?

Para primarmos pela especificidade defendida por Raffestin (2012), é oportuno ressaltar que sua análise sugere que se compreenda a concepção conceitual de territorialidade não como algo dado, construído e consolidado, mas como uma construção viva, cambiante, em constante processo de reconstrução e ressignificação.

Autores como Raffestin (2012) e Saquet (2013), de maneiras diferentes, apontam a territorialidade como um conjunto de relações sobre um dado território, e são essas relações, atividades ou práticas que criam ou mantêm esses territórios. A CIPOE tem diversas práticas territoriais, como: atendimentos de ocorrências nas escolas, construção de planos de segurança escolar, rondas escolares etc. Dentro dessas práticas, outras são desencadeadas e, na nossa leitura, todas essas são de disciplina. Disciplina dos sujeitos, dos cidadãos e dos corpos e, como consequência, produzem territórios disciplinares.

A respeito do tema "disciplina", Foucault desenvolveu extensa pesquisa nos seus livros e cursos no Collège de France. Acerca daquilo que ele denomina disciplina, ressaltou:

[a] disciplina é essencialmente centrípeta. Quero dizer que a disciplina funciona na medida em que isola um espaço, determina um segmento. A disciplina concentra, centra, encerra. O primeiro gesto da disciplina é, de fato, circunscrever um espaço no qual seu poder e os mecanismos do seu poder funcionarão plenamente e sem limites [...] (FOUCAULT, 2008, p. 58-59).

A disciplina age sobre os corpos e produz territórios disciplinares, criando regras e padrões. Segundo Foucault (2008), ela constitui-se de quatro elementos principais: 1) decomposição, 2) classificação, 3) sequenciamento e 4) adestramento progressivo e de controle permanente. A saber, se necessário for, a CIPOE divide (decompõe) e classifica seu espaço de atuação em diferentes tipologias, como zonas vermelhas, manchas criminais, territórios perigosos, território do tráfico etc. A companhia sequencia seus espaços e suas ações de modo coordenado, conectado e hierarquizado, pois percebemos territórios em formas de zonas que abrangem os municípios de Belém, Ananindeua e Marituba. Um exemplo é a $1^{\text {a }}$ RISP, que é dividida de modo hierarquizado pelo estado do Pará em AISPs, as quais também servem de suporte de atuação da CIPOE. Essa companhia, nas escolas dentro das malhas de sua atuação, molda (adestra) os corpos e os comportamentos, permanentemente, a partir de um conjunto de regras e padrões.

\footnotetext{
9 “[...] territorialidade é o conjunto de relações que os seres humanos mantêm com a exterioridade e alteridade, por meio de mediadores, para a satisfação de suas necessidades, no sentido de alcançar a maior autonomia possível [...] levando em consideração os recursos do sistema” (RAFFESTIN, 2012, p. 139, tradução nossa).
} 


\section{|Leildo Dias Silva |}

Pode-se dizer que a disciplina tem duas dimensões básicas, que são: a) vertical (exemplo: dividir, classificar, sequenciar e adestrar) e b) horizontal e, por consequência, espacial (também territorial). De acordo com Foucault (2008, p. 59), “[...] o primeiro gesto da disciplina é, de fato, circunscrever um espaço no qual seu poder e os mecanismos do seu poder funcionarão plenamente e sem limites". Se estabelecermos uma aproximação entre as reflexões daquele filósofo e nosso tema de análise, podemos perceber, no espaço de atuação da CIPOE, as diversas tessituras territoriais que a companhia elabora ou usa, todas com limites bem definidos (AISPs, STs e bairros).

No entanto, não devemos esquecer que a CIPOE não atua sozinha na tarefa de disciplinamento dos sujeitos e na produção de territórios de disciplina. A escola ${ }^{10}$ é, por excelência, disciplinadora ao instituir um conjunto de normas e regras que define formas de agir, maneiras de andar, padrões de vestimentas, modos de comportamentos, ao passo que proíbe tantos outros. Além dessas atribuições de caráter disciplinar, a escola, em alguma medida, atua como agente propulsor das ações da CIPOE. Em certas circunstâncias, a escola pode acionar formalmente a intervenção dessa companhia para "solucionar" determinados problemas disciplinares.

Foucault (2008) também estudou o nascimento e a "evolução" da polícia; segundo ele, ela atua sobre os corpos por meio da disciplina. Embora não possamos tomar as definições dele na íntegra, - pois, Foucault (2008) teve foco de análise o espaço-tempo europeu - interessam-nos alguns aspectos de caráter mais amplos, ligados à disciplina acerca da instituição polícia, com os quais podemos estabelecer alguns diálogos.

$\mathrm{Na}$ nossa leitura, as práticas disciplinares da CIPOE são práticas territoriais. Em outras palavras, são territorialidades que produzem territórios de dominação ${ }^{11}$ e de disciplina. Esses territórios, em função das suas territorialidades ou práticas disciplinares, são zonais, contíguos.

Antes de prosseguirmos à próxima seção, faz-se necessário dizer que o sistema territorial não acontece, na prática, de modo isolado ou desconectado, uma vez que ele é uno; ou seja, malhas, nós e redes estão imbricados e conectados a todo momento. A ênfase sobre os elementos das malhas, neste trabalho, é apenas uma questão analítica/metodológica para atender a seus objetos de pesquisa e análise.

\section{ESTADO, 'MÁQUINA' DE RECORTAR O ESPAÇO: os territórios da segurança pública e seus usos pela CIPOE}

10 A disciplina promovida pela escola e pela polícia são de naturezas diferentes. A primeira instituição tem disciplinamento de caráter formativo e, em alguma medida, emancipatório, ao passo que a segunda tem caráter de disciplinamento repressivo.

${ }^{11}$ Abordamos território de dominação no sentido daquele trabalhado por Rogério Haesbaert (2014). 


\section{|Leildo Dias Silva |}

Nesta seção, analisaremos a elaboração das malhas do território da segurança pública pelo estado do Pará e como essas malhas são utilizadas pelo policiamento escolar. Para que conseguíssemos essa análise, foram mobilizados os seguintes documentos: a Lei $n^{\circ}$ 7.584, de 28 de dezembro de 2011; a Resolução no 185, de 19 de fevereiro de 2012 e uma entrevista com o comandante da CIPOE, em 2017. A partir dessa legislação, e com os dados dos trabalhos de campo junto à companhia, elaboramos um quadro e quatro mapas que nos ajudam a espacializar e, em certa medida, sintetizar a catalogação dos documentos.

A referida companhia atua, efetivamente, em três municípios (Belém, Ananindeua e Marituba) e, portanto, esses se constituem nossa área de estudo. O Mapa 1, a seguir, além de localizar nossa área de estudo, traz os recortes dos bairros dos municípios aqui em tela. Assim, pode-se recorrer a esse mapa sempre que for preciso saber onde se localiza um determinado bairro. Nos demais mapas, a ênfase será dada a outras informações.

Depois dessas demarcações, voltemos ao objetivo desta seção. A CIPOE reordena o território de sua atuação em diversos recortes/malhas. Desses recortes, os principais são os STs, que serão estudados na próxima subseção. Porém, a CIPOE leva em consideração outras malhas, as quais são produzidas por hierarquias superiores à companhia em ênfase. Produzidas pela Secretaria de Estado de Segurança Pública e Defesa Social do Pará (SEGUP), essas malhas podem ser consideradas como da segurança pública do Pará. Tais recortes foram criados pela Lei $\mathrm{n}^{\circ}$ 7.584/2011, que dispõe sobre a reorganização do Sistema Estadual de Segurança Pública e Defesa Social (SIEDS), a reestruturação organizacional da SEGUP e dá outras providências. 


\section{| Leildo Dias Silva |}

Mapa 1 - Localização da área de estudo

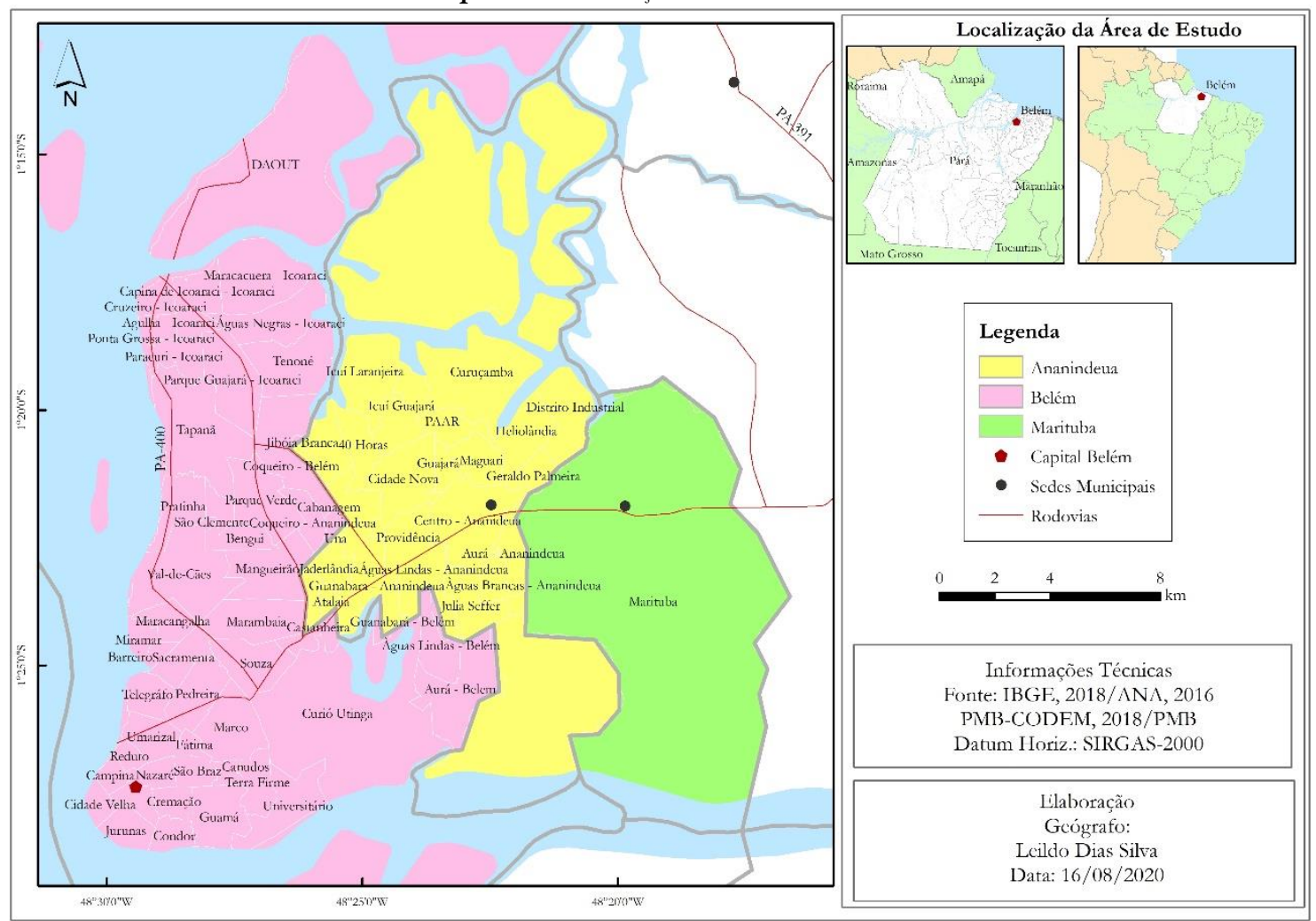

Fonte: IBGE, 2018/ANA, 2016; PMB-CODEM, 2018/PMB.

Em relação a essas malhas territoriais da segurança do Pará, a Lei no 7.584/2011 determina que o estado deve ser reordenado em RISPs. Em letras da lei:

Art. 18. A organização e a distribuição operacional dos órgãos supervisionados ficam delimitadas pelas Regiões Integradas de Segurança Pública - RISP, vinculando a sua desconcentração, principalmente no que se refere às suas divisões em circunscrições de atuação e gestão administrativa e financeira (PARÁ, 2012, p. 8).

De acordo com a referida lei, as RISPs foram divididas em AISPs, que, por sua vez, foram divididas em Setores Integrados de Segurança Pública e Defesa Social (SEISP). Em letras da lei:

As RISP serão divididas em Áreas Integradas de Segurança Pública e Defesa Social - AISP, e estas em Setores Integrados de Segurança Pública e Defesa Social - SEISP, conforme conveniência da Administração, com aprovação pelo Conselho Estadual de Segurança Pública - CONSEP (PARÁ, 2012, p. 8).

As RISPs e as AISPs são regulamentadas pela Resolução no 185/2012: “CONSEP aprova a delimitação circunscricional das Regiões Integradas de Segurança Pública - RISP, no Sistema Estadual de Segurança Pública e Defesa Social - SIEDS, e dá outras 


\title{
| Leildo Dias Silva |
}

providências." (PARÁ, 2012, p. 1). Em seu artigo 2º a resolução enuncia a criação de 15 RISPs, dentre as quais a $1^{\mathrm{a}}$ e a $2^{\mathrm{a}}$ abrangem a nossa área de estudo. São elas:

Art. $3^{\circ}$ As Regiões Integradas de Segurança Pública e Defesa Social - RISP, serão as seguintes:

$\int 1^{\circ}$. A $1^{\mathrm{a}}$ RISP - Região da Capital englobará o Município de Belém, seus distritos e ilhas, cujos órgãos de atuação serão os seguintes:

I - Na Polícia Militar, o Comando de Policiamento da Capital, com Sede em Belém, composto pelas Unidades abaixo especificadas.

$[\ldots]$

$\int 2^{\circ}$ A $2^{\text {a }}$ RISP - Região Metropolitana de Belém, englobará os Municípios de Ananindeua, Benevides, Marituba e Santa Bárbara do Pará, cujos órgãos de atuação serão os seguintes [...] (PARÁ, 2012, p. 1-2).

A resolução citada aponta mais divisões quanto às áreas de segurança pública, conforme versa seu artigo $4^{\circ}$ :

\begin{abstract}
As Regiões Integradas de Segurança Pública e Defesa Social - RISP poderão ser divididas em Áreas Integradas de Segurança Pública e Defesa Social (AISP), e estas em Setores Integrados de Segurança Pública e Defesa Social (SEISP), ${ }^{12}$ e estes em Subsetores (SUBSEISP) Integrados de Segurança Pública e Defesa Social (PARÁ, 2012, s/p).
\end{abstract}

As AISPs são formadas por dois ${ }^{13}$ ou mais bairros. Em cada uma delas, tem-se uma unidades executoras. A Resolução $\mathrm{n}^{\circ}$ 185/2012 institui as delimitações das AISPs, descrevendo-as da seguinte maneira:

[art. 5] $\int 1^{\circ}$. A $1^{\text {a }}$ AISP englobará os Bairros da Campina, Cidade Velha, Reduto e Umarizal. I - o perímetro da $1^{a}$ AISP compreenderá a poligonal que têm início na intersecção da Baía do Guajará com o prolongamento da Travessa José Pio, segue por esta até o canal do Galo, flete à direita e segue por este até encontrar a Travessa Nove de Janeiro, flete à direita e segue por esta até a Rua Boaventura da Silva, flete à direita e segue por esta até a Travessa Benjamim Constant, flete à direita e segue por esta até a Rua Henrique Gurjão, flete à esquerda e segue por esta até a Avenida Assis de Vasconcelos, flete à esquerda e segue por esta até o início da Rua Gama Abreu, flete à direita e segue por esta até a Avenida Almirante Tamandaré, segue por esta até a Avenida Dezesseis de Novembro, flete à esquerda e segue por esta até a Rua Cesário Alvim, flete à direita e segue por esta até encontrar a margem direita do Rio Guamá, flete à direita e segue por sua margem até o início da poligonal (PARÁ, 2012, s/p).

Dentro dessas AISPs, existem unidades executoras, como os batalhões e as companhias da PM. Os batalhões podem policiar/controlar mais de uma AISP, conforme mostra o Quadro 1, que traz, em seu bojo, todas as malhas territoriais da segurança pública da nossa área de estudo, com vistas ao uso da CIPOE em suas atividades. No decorrer

12 Acerca dos SEISP e dos Subsetores Integrados de Segurança Pública e Defesa Social (SUBSEISP), a presente pesquisa não conseguiu evidências de suas efetivações.

${ }^{13}$ A exceção é a $5^{\text {a }}$ AISP, formada apenas pelo bairro Guamá (ver o Quadro 1). 


\section{| Leildo Dias Silva |}

desta pesquisa, vamos, com exceção das RISPs, espacializar todos os recortes com que lida o policiamento escolar. Primeiro, iremos nos ater às malhas produzidas pela SEGUP e, depois, às malhas da CIPOE.

Quadro 1 - Recortes/malhas do policiamento escolar em Belém, Ananindeua e Marituba (Pará)

\begin{tabular}{|c|c|c|c|c|}
\hline RISP & ST $^{14}$ & BPM & AISP & Bairros, distritos e cidades \\
\hline \multirow{14}{*}{$1^{\mathrm{a}}$} & \multirow{6}{*}{1} & \multirow{2}{*}{$2^{\circ}$} & $1^{\mathrm{a}}$ & Umarizal, Campina, Reduto e Cidade Velha. \\
\hline & & & $2^{\mathrm{a}}$ & Nazaré, São Braz, Canudos e Fátima. \\
\hline & & \multirow{4}{*}{$20^{\circ}$} & $3^{\mathrm{a}}$ & Condor e Cremação. \\
\hline & & & $4^{\mathrm{a}}$ & Batista Campos e Jurunas. \\
\hline & & & $5^{\mathrm{a}}$ & Guamá. \\
\hline & & & $6^{\mathrm{a}}$ & Terra Firme e Universitário. \\
\hline & \multirow{3}{*}{2} & \multirow{3}{*}{$1^{\mathrm{o}}$} & $7^{\mathrm{a}}$ & Val-de-Cans, Sacramenta, Telégrafo, Barreiro, Miramar e Maracangalha. \\
\hline & & & $8^{\mathrm{a}}$ & Marco, Pedreira e Curió-Utinga. \\
\hline & & & $9^{\mathrm{a}}$ & Marambaia, Castanheira e Souza. \\
\hline & \multirow{5}{*}{3} & \multirow[t]{2}{*}{$24^{\circ}$} & $10^{\mathrm{a}}$ & $\begin{array}{l}\text { Parque Verde, Mangueirão, Cabanagem, Panorama XXI, Coqueiro- } \\
\text { Belém e Una. }\end{array}$ \\
\hline & & & $11^{\mathrm{a}}$ & Tapanã, Pratinha e São Clemente. \\
\hline & & \multirow{3}{*}{$10^{\circ}$} & $12^{\mathrm{a}}$ & $\begin{array}{l}\text { Distrito de Icoaraci: Maracacuera, Campina de Icoaraci, Cruzeiro, Ponta } \\
\text { Grossa, Agulha e Paracuri. }\end{array}$ \\
\hline & & & $13^{\mathrm{a}}$ & Icoaraci: Tenoné, Águas Negras e Parque-Guajará. \\
\hline & & & $14^{\mathrm{a}}$ & Distrito de Outeiro. \\
\hline \multirow{6}{*}{$2^{\mathrm{a}}$} & \multirow{6}{*}{4} & \multirow{4}{*}{$6^{\circ}$} & $17^{\mathrm{a} 15}$ & Providência, Jaderlândia, Atalaia, Coqueiro e Guanabara. \\
\hline & & & $18^{\mathrm{a}}$ & $\begin{array}{l}\text { Cidade Nova, Jiboia Branca, } 40 \text { Horas, Icuí-Guajará, Icuí-Laranjeira e } \\
\text { Guajará. }\end{array}$ \\
\hline & & & $19^{\mathrm{a}}$ & Águas Brancas, Aurá, Aurá-Belém, Julia Seffer e Águas Lindas. \\
\hline & & & $20^{\mathrm{a}}$ & Centro, Geraldo Palmeira, Heliolândia, Distrito Industrial e Maguari. \\
\hline & & $29^{\circ}$ & $21^{\mathrm{a}}$ & Paar e Curuçambá. \\
\hline & & $21^{\circ}$ & $22^{\mathrm{a}}$ & Cidade de Marituba. \\
\hline
\end{tabular}

Fonte: Elaborado própria com base no PGCIPOE 2016-2018 e na Resolução n 185, de 19/02/2012.

Os municípios de Belém, Ananindeua e Marituba têm, no total, 22 AISPs, ${ }^{16}$ sendo que o município de Marituba tem apenas a AISP 22a . A CIPOE, por ser uma companhia independente, ou seja, com autonomia e com atribuições de batalhão, segue também essas hierarquias de ordenamento das malhas do território da segurança pública do estado em tela.

Esse conjunto de legislação (Lei no 7.584/2011, Decreto n ${ }^{\circ}$ 1.625/2016 e Resolução no 185/2012), já apresentado, dá um caráter "legal” à produção das malhas no estado com vistas à segurança pública. Isso faz com que nos aproximemos das reflexões promovidas por Raffestin (1993), quando assevera que os traçados das malhas têm o objetivo de enquadramento do ou de um poder. Esse poder que se exerce dentro dessas malhas é, sobretudo, de disciplina e vigilância. Com isso, também nos aproximamos das reflexões

\footnotetext{
14 Os STs não fazem parte do sistema de segurança pública do estado do Pará, conforme a Resolução no 185 , de 19 de fevereiro de 2012. Eles são uma produção da CIPOE, constante seu plano de gestão de 2016 a 2018. 15 As AISPs $17^{\mathrm{a}}$ à $21^{\mathrm{a}}$ pertencem à cidade de Ananindeua/PA.

${ }^{16}$ Contudo, as 15. e 16. ${ }^{a}$ são pertencentes à Ilha de Mosqueiro, a qual, embora seja do município de Belém, não recebem os serviços prestados pela companhia.
} 


\section{| Leildo Dias Silva |}

feitas por Foucault (2008), que afirma que o primeiro gesto da disciplina é circunscrever (recortar) o espaço onde seu poder (disciplinar) funcionará plenamente.

A CIPOE usa os recortes territoriais da segurança pública do estado do Pará seguindo a hierarquia: 1) RISPs, 2) áreas de atuação dos BPM e 3) AISPs). Assim, é mister nos debruçarmos sobre essas malhas e espacializá-las. Os mapas 2 e 3, a seguir, mostram as AISPs e as áreas de atuação dos BPM, respectivamente, conforme a Resolução $\mathrm{n}^{\circ}$ 185/2012. Conectado a isso, o PGCIPOE/2016-2018 afirma que atribui funções ao policiamento de área, ou seja, a CIPOE pode atribuir ou pedir cooperação às companhias $\operatorname{orgânicas~}^{17}$ — que atuam nas AISPs — para que efetuem policiamento nas escolas dentro de suas circunscrições.

Essa atribuição, que se constitui como um dos objetivos do plano de gestão da companhia, dá-se em função de as AISPs serem áreas/malhas menores. Assim, como já apontava Raffestin (2012), o Estado recorta o espaço em malhas/tessituras no/do tamanho que julga adequado para ver o melhor possível. Em outros termos, recorta o espaço para melhor disciplinar, controlar e vigiar. De acordo com o PGCIPOE: "[...] o Comando da Corporação [CIPOE] opta por tornar comuns, nas unidades de policiamento de área (AISPs), práticas de policiamento escolar, assistencial e turístico, visto que essas temáticas especiais se mostram presentes no dia a dia do policiamento" (CIPOE, 2016, p. 10).

É de suma relevância dizer que, segundo o artigo 12 da Resolução no 185/2012:

Serão responsáveis pelas Áreas Integradas de Segurança Pública e Defesa Social, os Comandantes de Batalhões na Polícia Militar - excepcionalmente, os Comandantes de Companhias Independentes ou Orgânicas - e, na Polícia Civil, os Diretores de Seccionais - excepcionalmente, os Chefes de Unidades Policiais (PARÁ, 2012, s/p).

17 Ademais, é importante destacar que as AISPs que compõem a nossa área de estudo totalizam 20. Os batalhões de polícia militar são compostos por companhias orgânicas, e estas, por pelotões. 
|Tessituras de um território: o policiamento escolar na Grande Belém |

\section{| Leildo Dias Silva |}

Mapa 2 - Áreas Integradas de Segurança Pública e Defesa Social (AISP)

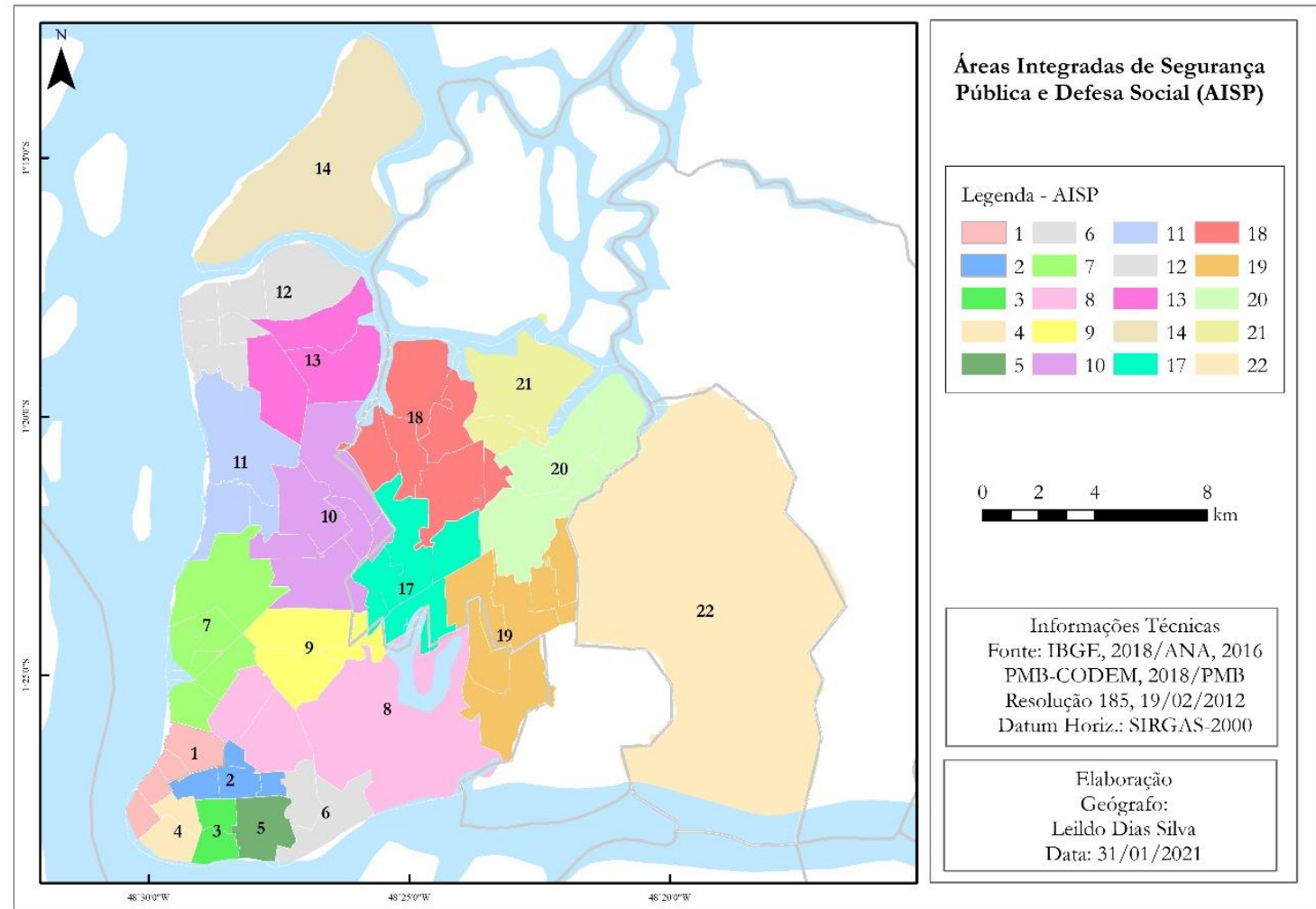

Fonte: IBGE, 2018/ANA, 2016; PMB-CODEM, 2018/PMB; Resolução n. 185, de 19/02/2012.

Mapa 3 - Áreas de atuação dos Batalhões de Polícia Militar de Belém, Ananindeua e Marituba, Pará

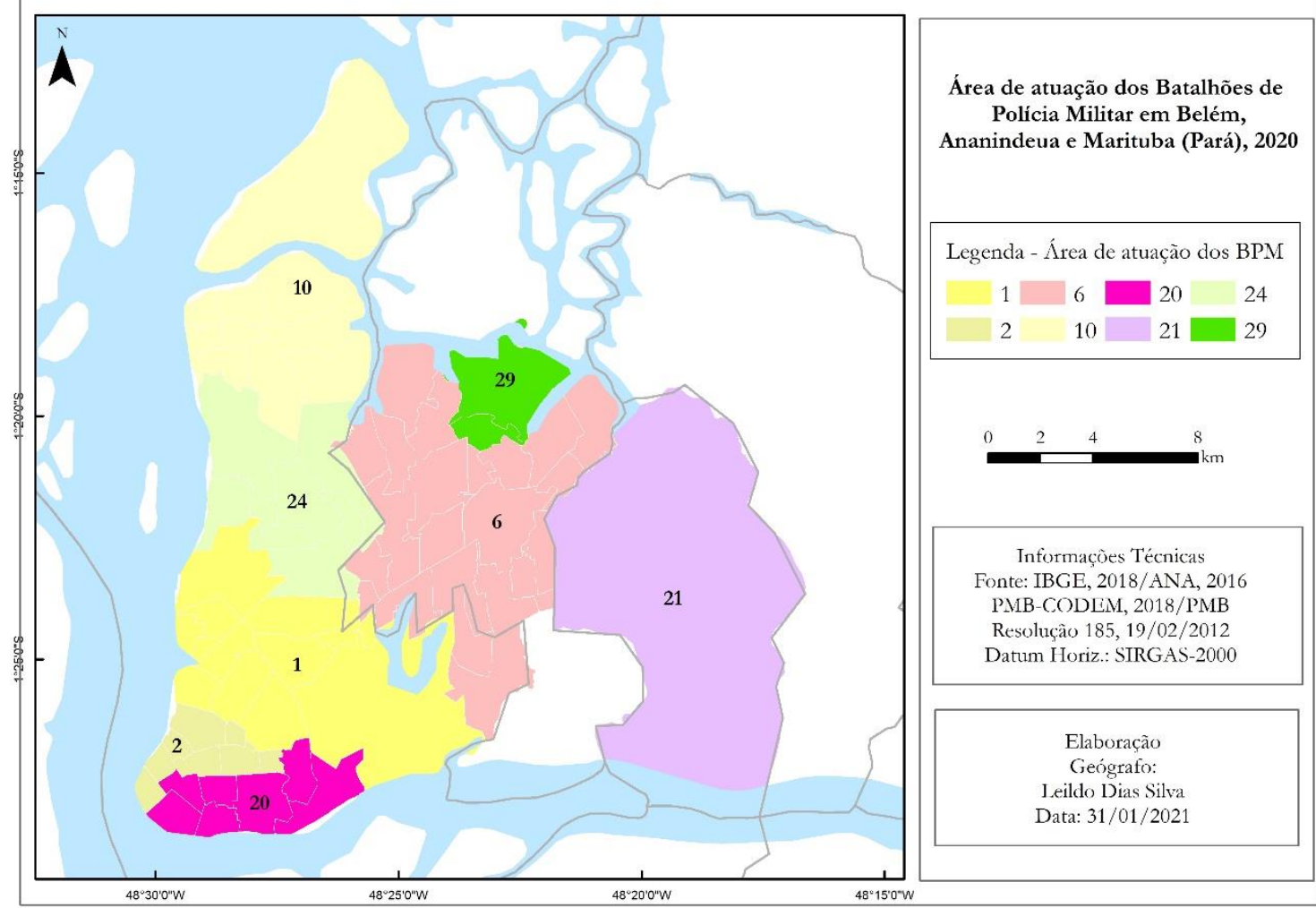

Fonte: IBGE, 2018/ANA, 2016; PMB-CODEM, 2018/PMB; Resolução n. 185, de 19/02/2012. 


\section{|Leildo Dias Silva |}

Além disso, dentro de cada uma das AISPs, tem-se um conjunto de atores/órgãos/instituições/elementos que atuam na execução do policiamento, que são: PM (batalhões, companhias e pelotões), Polícia Civil (seccionais, delegacias e unidades de polícia), corpo de bombeiros, viaturas, policiais, policiamento (ostensivo e especializado), delegados, investigadores etc.

As informações mostram que a produção e o funcionamento dos territórios da segurança pública dependem, grandemente, de uma rede interconectada pelos nós. Em outras palavras, depende daquilo que Souza (2008) chamou de substrato espacial material. Para o autor, o poder não é exercido sem contato ou referência à materialidade, embora o território não deva ser confundido com isso.

As unidades executoras de cada AISP são, quase sempre, as companhias orgânicas dos batalhões. O número de companhias orgânicas de cada batalhão depende, em grande medida, do número de AISPs que tem dentro das circunscrições de cada batalhão (sobre a espacialização das áreas de atuação dos batalhões e das AISPs, ver os Mapas 2 e 3).

Ainda sobre o substrato espacial material tratado em Souza (2008), nota-se que ele influencia, de maneira direta, na produção das malhas/tessituras da segurança pública, pois, quanto mais próximas da área central da Grande Belém, ${ }^{18}$ menores são as malhas. Por conseguinte, quanto mais afastadas do centro da grande cidade, maiores são as áreas das AISPs. Ou seja, tem-se uma "lógica" de produção das tessituras em centro-periferias. Para cada uma dessas áreas, o projeto/programa muda. O centro precisa passar a sensação de seguro, bem policiado, então, a polícia precisa fazer mais rondas, tem de estar mais presente, tem de ser vista (visibilidade) (DIAS SILVA, 2020) e possui mais equipamentos urbanos da segurança pública — nós (seccionais, delegacias, unidades e batalhões, etc.). Por outro lado, nas periferias, a polícia nem sempre é vista e percebida como sinônimo de segurança, mas de temor, o que evidencia que sua atuação é, sobretudo de disciplina, que atua sobre os corpos, mentes e, por consequência, na produção de territórios disciplinares.

Todas essas malhas e redes estão, também, a serviço do policiamento escolar. Desde que seja necessário, o policiamento dos batalhões e suas companhias orgânicas podem ser acionados pela companhia de policiamento escolar. Como já mostramos anteriormente, isso consta no PGCIPOE 2016-2018. Da mesma maneira, a rede de delegacias e a DATA servem de apoio ao trabalho da CIPOE. Por exemplo, se a ocorrência for praticada por um estudante maior de 18 anos de idade, dependendo da gravidade atribuída ao ato, esse aluno poderá ser conduzido à unidade/delegacia mais próxima da

18 Considera-se como área central de Belém os bairros do Umarizal, Nazaré, Batista Campos e algumas áreas dos bairros da Campina, São Brás e Marco (ver o Mapa 1). 
| Leildo Dias Silva |

escola; se menor de 18 anos de idade, será conduzido à DATA. Na próxima seção, vamos nos ater à produção das malhas da CIPOE.

\section{CIPOE: as tessituras do território do policiamento escolar na Grande Belém}

Dentro da execução do policiamento, temos, além dos BPM, outras unidades executoras, que são as companhias independentes de policiamento. Essas têm as mesmas atribuições dos batalhões, contudo, são menores, chegando a um efetivo de mais ou menos de 150 agentes. Além disso, tais companhias são divididas em pelotões. Dito isso, nesta subseção vamos utilizar como documentos e materiais de análise o PGCIPOE 2016-2018 e uma entrevista com o comandante dessa companhia em 2017.

Vale dizer que as companhias independentes têm sua responsabilidade por temas específicos, como policiamento escolar, policiamento turístico etc., e têm um vasto território que está ou deveria estar sob o seu controle. A CIPOE, por exemplo, tem responsabilidade pelo policiamento escolar em todo o estado, mas, como já apontamos, restringe-se, praticamente, aos três municípios citados aqui. Ainda assim, esses três municípios são um vasto território com alto grau de complexidade, que leva a CIPOE a buscar maneiras de reordená-lo/recortá-lo (com uma lógica própria) em STs. Veja o Mapa 4, a seguir.

Acerca da atuação da CIPOE, destacamos que:

\footnotetext{
Esta companhia atua através da Ronda Escolar, que atende atualmente o número de 315 (trezentas e quinze) escolas estaduais, distribuídas na Região Metropolitana de Belém, e conta com, em média, 03 (três) viaturas por dia e 03 (três) motocicletas, ocasião em que distribui seu o efetivo, alocando-o em 04 setores territoriais [STs] de policiamento escolar (CIPOE, 2019, s/p).
}

Porém, mesmo tendo uma lógica própria, o reordenamento dessa companhia está diretamente relacionado a outras lógicas territoriais, como as áreas de atuação dos BPM e as AISPs, diante do conhecimento de que a CIPOE tem um efetivo reduzido para uma área territorial vasta e, por isso, precisa usar os serviços dos batalhões e companhias orgânicas.

No Mapa 4, os STs são agrupamentos de bairros na cidade de Belém e o agrupamento das cidades de Ananindeua e Marituba forma um único ST. Dos quatros STs, três fazem parte da cidade de Belém. Como pode ser observado no referido mapa, quanto mais central é a área, menor é área do ST. 


\section{|Leildo Dias Silva |}

Mapa 4 - Setores Territoriais de Policiamento Escolar Ordinário da CIPOE

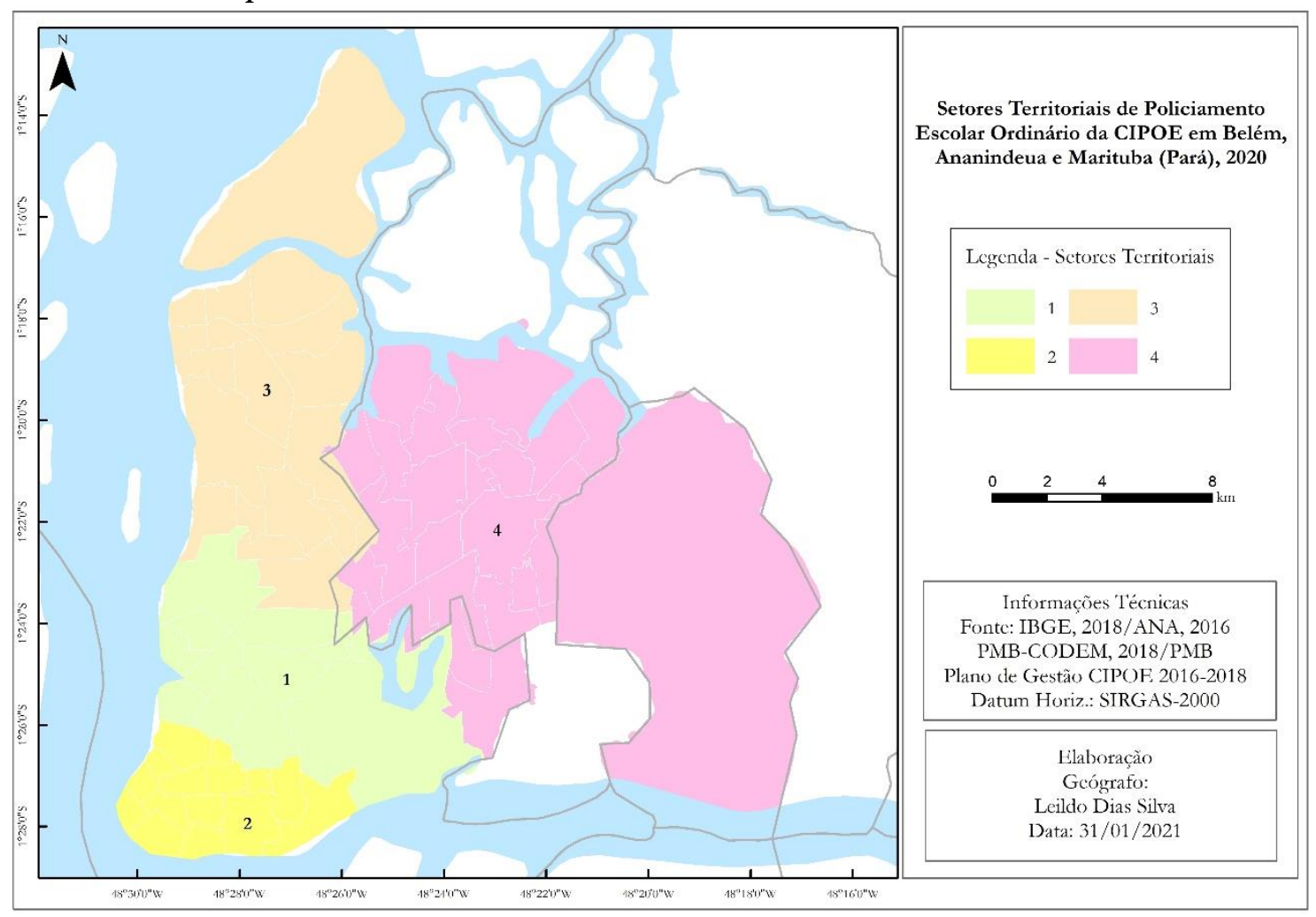

Fonte: IBGE, 2018/ANA, 2016; PMB-CODEM, 2018/PMB; Plano de Gestão CIPOE 2016—2018.

O Comandante 1 da CIPOE, em 2017, nos disse que essa setorização (ST) tem relações diretas com os BPM. Sobre isso, afirmou:

O $1 .^{\circ}$ setor [de policiamento escolar] corresponde ao $1 .^{\circ}$ Batalhão de policiais que estabelece uma boa relação com as unidades diárias, então o $10^{\circ}$ Batalhão é a área do Entroncamento [Castanheira], Telégrafo, Barreiro, Marambaia, Pedreira, etc. O 2. ${ }^{\circ}$ setor corresponde ao $2 .^{\circ}$ Batalhão e ao $20{ }^{\circ}$ Batalhão. O 2. ${ }^{\circ}$ Batalhão é o Comércio, São Braz. O 20. Batalhão é área de Jurunas, Cremação, Condor. O 3. ${ }^{\circ}$ Setor corresponde a área do nosso $10 .^{\circ}$ Batalhão e o $24 .^{\circ}$ Batalhão é o Bengui e Pratinha, e o $4 .^{\circ}$ setor fica com aquela área de Ananindeua pra lá, que corresponde ao nosso $6 .^{\circ}$ Batalhão, 26. ${ }^{\circ}$ e 29..$^{\circ}$ [BPM] (COMANDANTE 1 CIPOE, 2016).

A CIPOE tem uma "lógica" de reordenação do seu território de ação. No entanto, algumas dificuldades surgiram em função dessa companhia nem sempre considerar a cartografia oficial das cidades em que atua. Algumas vezes, a CIPOE considera conjuntos habitacionais como bairros e não considera a divisão em bairros dos Distritos de Belém, tomando-os com um bairro único. Além disso, considera Marituba sem divisões de bairros. Por questões analíticas/metodológicas, nós adequamos as diferenças à cartografia oficial das cidades de Belém e Ananindeua.

A construção desse reordenamento territorial, executado pela companhia, é um dos objetivos estratégicos do PGCIPOE. Em um trecho dele, é destacado que: 


\section{| Leildo Dias Silva |}

8.6. [objetivo estratégico] MELHORAR A ACESSIBILIDADE À SEGURANÇA ESCOLAR: Proporcionar condições para facilitar o acesso das comunidades escolares à metodologia e procedimento da CIPOE.

8.6.1 Setorizar o policiamento escolar, atribuindo responsabilidade territorial sobre os espaços dentro da CIPOE (CIPOE, 2016, p. 14 - itálico nosso).

Esse objetivo estratégico resultou nos STs, como mostra o Mapa 4. No documento da CIPOE, é denominado "Mapa dos Setores de Policiamento Escolar na $1^{\mathrm{a}}$ e $2^{\mathrm{a}}$ RISP" e se apresenta em forma de quadro, que aponta: a) escolas policiadas; b) Unidade Subregional de Ensino (USE); c) bairros; d) conselhos tutelares; e) unidades da PM local (unidades da PM, batalhões, AISPs, seccionais, delegacias etc.) e STs. São essas unidades e órgãos que compõem parte da trama territorial do policiamento escolar na Grande Belém. Inclui-se, ainda nessa trama, a DATA.

Evidencia-se que essas ações desses atores/instituições/órgãos/unidades é de suma importância para a execução do poder disciplinar da CIPOE nas escolas dentro dos limites de suas malhas. Todas as práticas diárias, executadas por um dado ator, são consideradas territorialidades, de acordo com Saquet (2013), embora saibamos que essas territorialidades da CIPOE produzem territórios de dominação. Aproximando-nos das reflexões de Raffestin (2012), quando esse trata de territorialidade, pode-se dizer que são essas malhas que, também, possibilitam a maior "satisfação" ou, em outros termos, o maior êxito no exercício do poder (de polícia) disciplinar e o maior controle de indivíduos dentro desses territórios.

São essas malhas que possibilitam que a CIPOE planeje, distribua e execute o seu programa - enquanto ator sintagmático que é - e suas atividades, como as rondas escolares, o atendimento de ocorrências em meio escolar e a elaboração de planos de segurança. São essas práticas (ações/movimentos) que ativam a territorialidade do policiamento escolar. Isso permite nossa aproximação das reflexões de Souza (2008), quando entende que são as ações que ativam as territorialidades.

Essas práticas/ações/territorialidades da CIPOE são todas práticas de disciplina, uma vez que o "simples" fato de a PM estar na escola já exerce um poder de disciplinamento. Entende-se, sobre isso, que o êxito da polícia se dá quando essa não necessita lançar mão do seu poder legítimo de uso da força, pois isso significa que as regras, os procedimentos etc. são eficientes; ou seja, a disciplina está funcionando dentro da "normalidade" (FOUCAULT, 2008).

E o que muda da lógica da produção das malhas da SEGUP (malhas da segurança pública do estado) para as malhas da CIPOE? Na nossa leitura, a mudança é tão somente a designação de uma companhia independente ao policiamento escolar. A diferença reside 


\section{|Leildo Dias Silva |}

em que a segunda tem autonomia para planejar as suas ações, enquanto as companhias orgânicas têm o seu planejamento elaborado pelos BPM. Mas, ambas as companhias são militares; ambas as "lógicas" de criação das malhas levam em consideração o substrato espacial material centro-periferia. Assim, quanto mais próximas ao centro, menores são as malhas. As lógicas e as companhias usam as mesmas redes para direcionar os infratores.

\section{CONCLUSÕES}

Diante dos resultados encontrados pela presente pesquisa, conclui-se que o Estado produz, de modo hierarquizado, diversas malhas territoriais, tais como, RISP, áreas de atuação dos BPM, AISP e ST, denominadas sistema da segurança pública. Cada hierarquia têm funções ao exercício do poder (disciplinar), que lhes cabe, de modo coordenado. Traçar malhas em um dado espaço é a maneira mais elementar da projeção de poder sobre ele e, portanto, da produção de territórios. E, conforme foi mostrado, no âmbito da segurança pública, o Estado faz isso com maestria na Grande Belém.

A prática de produzir tessituras, por parte da SEGUP e da CIPOE, pode ser compreendida como uma maneira de territorialidade dessas instituições. Essas malhas se efetivam no espaço e trazem (ou produzem) consigo um sistema territorial (malhas, nós e redes) complexo para disciplinamento das pessoas que estão dentro de seus limites.

O policiamento escolar, a CIPOE, é parte do sistema territorial da segurança pública e, portanto, faz uso de suas malhas ao mesmo tempo que também produz as suas próprias, no caso, os STs. Isso sugere que o policiamento escolar, aqui analisado como um mecanismo disciplinar, possui elevado grau de refinamento e de conexão com outras hierarquias.

Compete-nos lembrar que a produção dessas tessituras não é ingênua, mas faz parte de um dado projeto/programa. Isso se evidencia quando as instituições, tratadas aqui, recortam as malhas levando em consideração o substrato espacial material centro-periferias. Para cada espaço desses, existem objetivos diferenciados de disciplinamento.

A presença da polícia na escola, espaço onde ela era/é negada, nada mais é do que um aperfeiçoamento dos mecanismos disciplinares e de controle do Estado e da sociedade brasileira. O policiamento escolar analisado neste artigo faz parte das diferentes maneiras pelas quais a militarização da sociedade brasileira se faz presente. Esse tipo de policiamento é apenas uma das faces da militarização da vida urbana. A esse respeito, podemos citar diversos exemplos: no Pará, têm-se comunidades e bairros periféricos "ocupados" por agentes policiais no programa de governo nomeado de "Territórios pela Paz"; no Rio de Janeiro, tem-se a ocupação das comunidades pelas Unidades de Polícias Pacificadoras e, em 
2018, esse mesmo estado recebeu intervenção militar. Essas ações e práticas corroboram com a construção de discursos cada vez mais recorrentes em defesa da presença dos agentes militares nos mais variados espaços públicos.

O tema do policiamento escolar ainda é pouco pesquisado e, portanto, para se ter mais clareza de como esse mecanismo se processa, é necessário que mais estudos sejam desenvolvidos. Nas próximas pesquisas, pretende-se analisar os atendimentos de ocorrências no meio escolar, a construção de planos de segurança nas escolas e a leitura da comunidade escolar, alvo da atuação da CIPOE, sobre esse policiamento.

\section{AGRADECIMENTOS}

Ao Conselho Nacional de Desenvolvimento Científico e Tecnológico (CNPq) pela bolsa de pesquisa sob n ${ }^{\circ}$ 130606/2018-9. Ao professor Dr. Durbens Martins Nascimento pelo processo de orientação e pela leitura crítica do presente artigo.

\section{REFERÊNCIAS}

CIPOE. Ofício descritivo das ações da CIPOE. Belém, PA, 2019.

Plano de Gestão CIPOE 2016-2018. CIPOE/PM: Belém, Pará, 2016.

DIAS SILVA, Leildo. As geografias do policiamento escolar : análise do policiamento nas escolas de Belém, Ananindeua e Marituba, Pará (2012 a 2019). 2020. 166 f. Dissertação (Mestrado em Planejamento do Desenvolvimento) - Universidade Federal do Pará, Belém, 2020. Disponível em: <https://drive.google.com/file/d/1tHlrSMETvn8vzDZcp1Po3HSo'T-rybbD/view $>$. Acesso em 31/01/2021.

FOUCAULT, Michel. Microfísica do poder. 20. ed. Rio de Janeiro: Edições Graal, 2004 [1979].

FOUCAULT, Michel. Segurança, território e população: curso dado no College de France (1977-1978. Tradução Eduardo Brandão. São Paulo: Martins Fontes, 2008. (Coleção tópicos).

HAESBAERT, Rogério. Viver no limite: território e multi/transterritorialidade em tempos de in-segurança e contenção. Rio de Janeiro: Bertrand Brasil, 2014. 320 p.

PARÁ. Decreto $\mathbf{n}^{\mathbf{0}} \mathbf{1 . 6 2 5}$, de 18 de outubro de 2016. Regulamenta a Lei Complementar $\mathrm{n}^{\circ}$ 053, de 7 de fevereiro de 2006, alterada pela Lei Complementar $n^{\circ} 93$, de 15 de janeiro de 2014, que dispõe sobre a organização básica da Polícia Militar do Estado do Pará, e dá outras providências. Disponível em: $<$ http://www.faspm.pa.gov.br/sites/default/files/regulamento da lei compl 05306 lob .pdf>. Acesso em 24 de dezembro de 2019. 
Lei $\mathbf{n}^{\mathbf{0}} \mathbf{7 . 5 8 4}$, de 28 de dezembro de 2011. Dispõe sobre a reorganização do Sistema Estadual de Segurança Pública e Defesa Social -SIEDS, e da reestruturação organizacional da Secretaria de Estado de Segurança Pública e Defesa Social - SEGUP, e dá outras providências. Disponível em: <http://www.segup.pa.gov.br/sites/default/files/leino-7.584rest.segup regimento interno 0.pdf>. Acesso em 12 out. 2019.

Resolução $\mathbf{n}^{\mathbf{0}} \mathbf{1 8 5}$, de 19 de fevereiro de 2012. CONSEP Aprova a delimitação circunscricional das Regiões Integradas de Segurança Pública - RISP, no Sistema Estadual de Segurança Pública e Defesa Social - SIEDS, e dá outras providências. Disponível em: < https://www.sistemas.pa.gov.br/sisleis/legislacao/302>. Acesso em: 12 out. 2019.

RAFFESTIN, C. A produção das estruturas territoriais e sua representação. In: SAQUET, M. A.; SPOSITO, E. S. Territórios e territorialidades: teorias, processos e conflitos. (Org.) - $1^{\mathrm{a}}$ ed. - São Paulo: Expressão Popular: Unesp. Programa de Pós-Graduação em Geografia, 2008. 368 p.

Espaço, território e territorialidade. Environment and Planning D: Society and Space, v. 30, p. 121-41, 2012.

Ática, 1993.

Por uma Geografia do Poder. Tradução de Maria Cecília França. São Paulo (SP):

SAQUET, Marcos Aurélio. Por uma abordagem territorial. In: SAQUET, Marcos Aurélio; SPOSITO, Eliseu Savério (Org.). Territórios e territorialidades: teorias, processos e conflitos. São Paulo: Expressão Popular, 2008. p. 73-94.

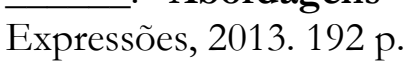

Proposições para estudos territoriais. GEOgraphia, Rio de Janeiro, ano 8, n. 15, p. $71-85,2006$.

SOUZA, Marcelo Lopes de. "Território" da divergência (e da confusão): em torno das imprecisas fronteiras de um conceito fundamental. In: SAQUET, Marcos Aurélio; SPOSITO, Eliseu Savério (Org.). Territórios e territorialidades: teorias, processos e conflitos. São Paulo: Expressão Popular, 2008. p. 57-72.

O território: sobre espaço e poder, autonomia e desenvolvimento. In: CASTRO, Iná Elias de [et al.] (Org.). Geografia: conceitos e temas. Rio de Janeiro: Bertrand Brasil, 1995.

Os conceitos fundamentais da pesquisa sócio-espacial. Rio de Janeiro: Bertrand Brasil, 2013. v. 1. 319 p.

\section{Como citar:}

\section{ABNT}

DIAS SILVA, L. Tessituras de um território: o policiamento escolar na Grande Belém. InterEspaço: Revista de Geografia e Interdisciplinaridade, v. 7, e202111, 2021. 


\section{|Leildo Dias Silva |}

Disponível em: <http://dx.doi.org/10.18764/2446-6549.e202111>. Acesso em: 28 jun. 2021.

\section{APA}

Dias Silva, L. Tessituras de um território: o policiamento escolar na Grande Belém. InterEspaço: Revista de Geografia e Interdisciplinaridade, v. 7, e202111. Recuperado em 28 junho, 2021, de http://dx.doi.org/10.18764/2446-6549.e202111

\section{@creative}

This is an open access article under the CC BY Creative Commons 4.0 license.

Copyright (C) 2021, Universidade Federal do Maranhão.

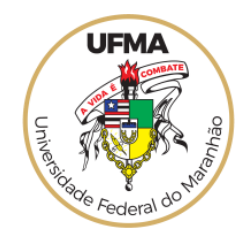

